This is an electronic reprint of the original article. This reprint may differ from the original in pagination and typographic detail.

Author(s): Tero, Tiia-Riikka; Salorinne, Kirsi; Lehtivuori, Heli; Ihalainen, Janne; Nissinen, Maija

Title: $\quad$ The structural diversity of benzofuran resorcinarene leads to enhanced fluorescence

Year: $\quad 2014$

Version:

Please cite the original version:

Tero, T.-R., Salorinne, K., Lehtivuori, H., Ihalainen, J., \& Nissinen, M. (2014). The structural diversity of benzofuran resorcinarene leads to enhanced fluorescence. Chemistry - An Asian Journal, 9(7), 1860-1867.

https://doi.org/10.1002/asia.201402016

All material supplied via JYX is protected by copyright and other intellectual property rights, and duplication or sale of all or part of any of the repository collections is not permitted, except that material may be duplicated by you for your research use or educational purposes in electronic or print form. You must obtain permission for any other use. Electronic or print copies may not be offered, whether for sale or otherwise to anyone who is not an authorised user. 


\title{
Structural Diversity of Benzofuran Resorcinarene Leads to Enhanced Fluorescence
}

\author{
Tiia-Riikka Tero, ${ }^{[\mathrm{a}]}$ Kirsi Salorinne, ${ }^{[\mathrm{a}]}$ Heli Lehtivuori, ${ }^{[\mathrm{b}]}$ Janne A. Ihalainen ${ }^{[\mathrm{b}]}$ and Maija \\ Nissinen*[a]
}

\begin{abstract}
An unexpected and previously unknown resorcinarene mono-crown with a fused benzofuran moiety in its macrocyclic core was obtained as a by-product from a bridging reaction of tetramethoxy resorcinarene with tetraethylene glycol ditosylate. The formation of the fused benzofuran moiety in the resorcinarene macrocycle resulted in a unique rigid
\end{abstract}

and puckered boat conformation as shown by XRD studies in the solid state. The modification of the macrocycle was also observed to affect the photophysical properties in solution by enhancing the fluorescence brightness compared to a conventional resorcinarene macrocycle. The fluorescent properties enabled a unique detection of structural features, i.e. the rigid boat conformation with the conjugated benzofuran system and the more flexible crown bridge part, in solution.

Keywords: resorcinarene $\bullet$
calixarene $\bullet$ benzofuran
fluorescence $\bullet$ supramolecular
chemistry $\bullet$ X-ray crystallography

\section{Introduction}

Resorcinarenes, a class of calixarene type macrocycles, have been widely investigated during the last few decades due to their advantageous features as concave host molecules, as well as, their versatile functionalization of the upper and lower rims leaving the aromatic cavity virtually intact during the synthesis. ${ }^{[1]}$ Modifications affecting the upper rim of the resorcinarene core include, for example, the synthesis of cavitands, in which the resorcinarene macrocycle is rigidified into a fixed crown conformation by a covalent bridge between the neighboring phenolic hydroxyl groups, ${ }^{[2]}$ as well as tetrabenzoxazine resorcinarenes, in which the resorcinol rings of the macrocycle and their hydroxyl groups form a benzoxazine ring with an amine..$\left.^{[}{ }^{3}\right]$ However, these functionalizations still leave the actual macrocyclic core more or less intact affecting only the functional groups on the upper rim. Closely related pyrogallarene macrocycles, on the other hand, have

[a] M. Sc. T.-R. Tero, Dr. K. Salorinne, Prof. M. Nissinen

Department of Chemistry, Nanoscience Center

University of Jyväskylä

P.O. Box 35, 40014 JYU (Finland)

E-mail: maija.nissinen@jyu.fi

[b] Dr. H. Lehtivuori, Prof. J. A. Ihalainen

Department of Biological and Environmental Science, Nanoscience Center University of Jyväskylä

P.O. Box 35, 40014 JYU (Finland)

Supporting information for this article is available on the WWW under http://dx.doi.org/10.1002/asia.200xxxxx. shown inherent structural instability due to the ability of the aromatic rings to transform into lactone rings in dilute solutions. ${ }^{[4]}$ Although the lactone structures were not successfully isolated and the lactone formation was exclusively stated as a property of pyrogallararenes, it proves that under certain conditions modification directly affecting the aromatic macrocyclic core is attainable.

An intriguing way to enhance the capacity of resorcinarenes in, for example, sensor applications is to functionalize them with a photoactive subunit, ${ }^{[5,6]}$ as e.g. in dansylated fluorescent resorcinarenes ${ }^{5}$ that have been exploited in sensing transition metals. Cavitand derivatives having either bulky fluorescent groups extending the walls of the cavity or flexible crown ether podand arms with a fluorescent moiety, have been demonstrated to work as fluorescent receptors for different metals ${ }^{[7]}$, anionic guests ${ }^{[8]}$ and ammonium compounds ${ }^{[9]}$, or function as molecular switches ${ }^{[10]}$ or in biological applications to sense e.g. guanosine $5^{\prime}$-triphosphate. ${ }^{[11]}$

Recently, by serendipity we succeeded to isolate a previously unknown resorcinarene by-product (1) from a reaction mixture of tetramethoxy resorcinarene bis-crown $(\mathbf{3})^{[12]}$ and mono-crown $(\mathbf{2})^{[13]}$ derivatives. To our surprise, the previously untouched resorcinarene core had one of the aromatic rings been replaced by a benzofuran moiety (Scheme 1) and, as at first observed with a naked eye under UV-light $(366 \mathrm{~nm}$, Figure S3), the benzofuran mono-crown derivative 1 showed intrinsic enhanced photophysical properties without having a separate fluorescent functionalization.

In this paper, we report the synthesis and discuss the possible reaction mechanism of the novel benzofuran mono-crown derivative 1. In addition, we report the structural characteristics arising from 


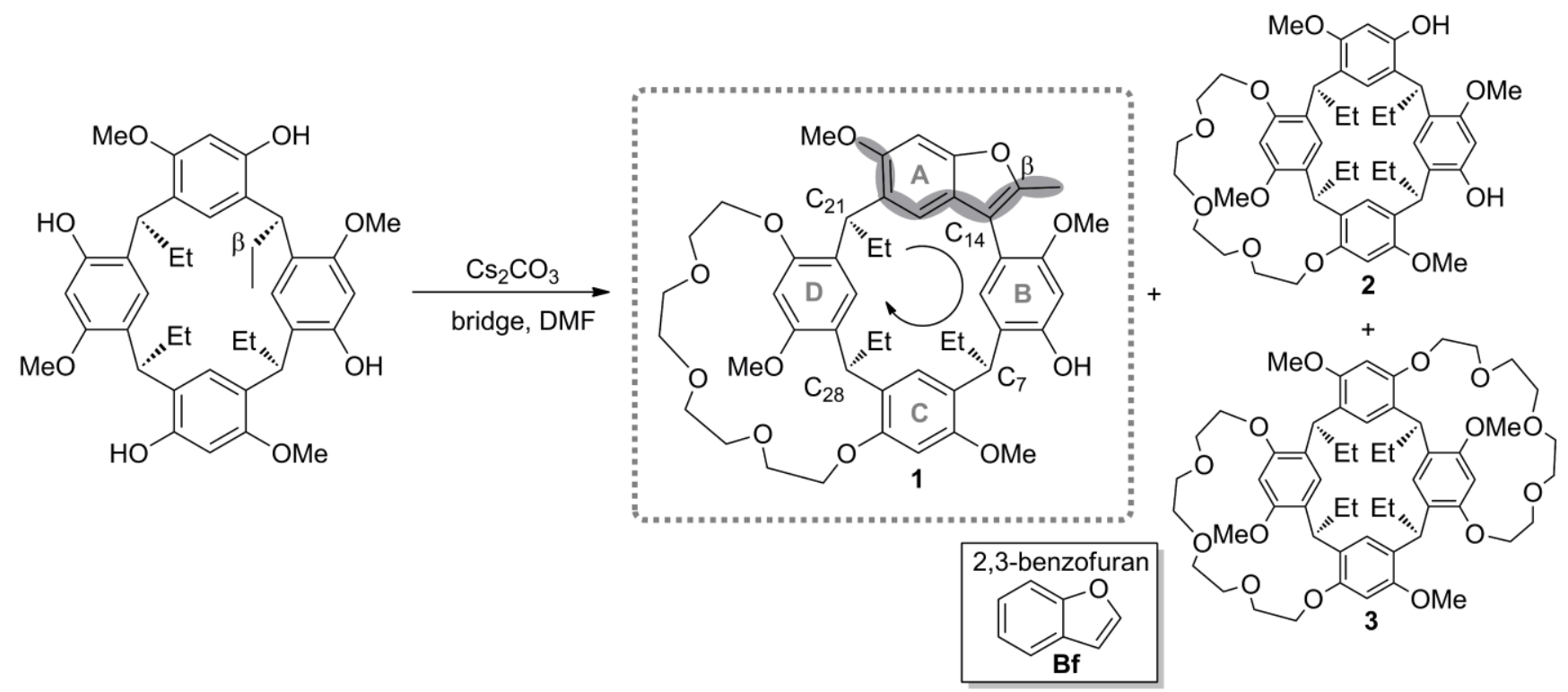

Scheme 1. Synthesis of the resorcinarene crown ethers: benzofuran mono-crown (1), mono-crown (2) and bis-crown (3) derivatives, and a structure of 2,3-benzofuran (Bf). $\beta$-Carbon and crystallographic numbering of the methine plane are indicated. The conjugated system formed by the benzofuran moiety is highlighted with bold grey line.

the fused benzofuran ring that were observed both in the solid state and in solution by means of X-ray crystallography and 2D fluorescence measurements. The main focus of the fluorescence studies was to discover which structural features induce the enhanced fluorescence of the benzofuran resorcinarene mono-crown 1.

\section{Abstract in Finnish: \\ Tetrametoksiresorsinareenin ja tetraetyleeniglykoliditosylaatin silloitusreaktiossa saatiin sivutuotteena ennalta odottamaton ja aiemmin tuntematon silloitettu resorsinareenijohdannainen, jonka makrosyklirunko oli merkittävästi muuttunut radikaalireaktiossa muodostuneen bentsofuraanirenkaan takia. Kiderakennetutkimuksissa havaittiin, että bentsofuraaniosa aiheuttaa makrosyklirungon vääntymisen voimakkaasti vääristyneeseen venekonformaatioon. Lisäksi makrosyklirungon muokkaus vaikutti yhdisteen valokemiallisiin ominaisuuksiin vahvistamalla sen fluoresenssin kirkkautta verrattuna tavanomaiseen resorsinareenimakrosykliin. Yhdisteen \\ fluoresenssiominaisuudet mahdollistivat yhdisteen rakenneominaisuuksien - jäykän venekonformaation, konjugoituneen bentsofuraanirenkaan ja joustavan kruunueetterisiltakappaleen - ainutlaatuisen havainnoimisen liuostilassa.}

\section{Results and Discussion}

\section{Synthesis}

The synthesis protocol established for the preparation of resorcinarene mono-crown derivative 2 by a nucleophilic reaction of tetramethoxy resorcinarene ${ }^{[14]}$ with one equivalent of tetraethylene glycol ditosylate in the presence of anhydrous $\mathrm{Cs}_{2} \mathrm{CO}_{3}$ in DMF at $90{ }^{\circ} \mathrm{C}$, was also shown to produce a previously unknown
Table 1. Reaction conditions for the synthesis of resorcinarene benzofuran mono-crown $\mathbf{1}$, resorcinarene mono-crown $\mathbf{2}$ and bis-crown $\mathbf{3}$ derivatives.

\begin{tabular}{|c|c|c|c|c|c|c|c|}
\hline \multirow{3}{*}{ Entry } & \multicolumn{7}{|c|}{ Yields (\%) } \\
\hline & Solvent & $\mathrm{T}\left({ }^{\circ} \mathrm{C}\right)$ & & & & $X^{a}$ & NB \\
\hline & & & 1 & 2 & 3 & & \\
\hline 1 & DMF & 90 & 5.2 & 8.5 & 13.2 & 0.37 & \\
\hline 2 & DMF & 60 & - & - & 12.0 & 0.18 & \\
\hline 3 & DMF & 90 & - & 1.1 & 8.9 & 0.14 & bridge, $2.2 \mathrm{eq}$ \\
\hline 4 & DMF & 60 & $<2$ & 3.9 & 11.2 & 0.24 & $\mathrm{~K}_{3} \mathrm{Fe}(\mathrm{CN})_{6}$ \\
\hline 5 & DMF & 90 & 6.1 & 8.1 & 10.0 & 0.32 & $\mathrm{~K}_{3} \mathrm{Fe}(\mathrm{CN})_{6}$ \\
\hline
\end{tabular}

${ }^{a}$ Reaction conversion $X=\left(\right.$ moles of tetramethoxy resorcinarene ${ }^{[14]}$ reacted $) /($ moles of TMR fed)

resorcinarene mono-crown derivative $\mathbf{1}$ as a by-product in addition to the earlier reported resorcinarene mono- $\mathbf{2}$ and bis-crown $\mathbf{3}$ derivatives (Scheme 1). ${ }^{[13]}$ The ratio of the three resorcinarene crown derivatives 1-3 was determined to be 2:3:5, respectively, and the isolated yield of the by-product 1 was $5.2 \%$ (Table 1, entry 1). The unusual structure of compound $\mathbf{1}$ with benzofuran ring as a part of the resorcinarene skeleton was characterized by means of NMR spectroscopy $\left({ }^{1} \mathrm{H},{ }^{13} \mathrm{C}, \mathrm{HMBC}\right.$ and HMQC), mass spectrometry (accurate mass, $\mathrm{ESI}^{+}$) and X-ray crystallography, which revealed the unexpected formation of the benzofuran unit inducing an elongated conjugated system with the alternating $\sigma$ - and $\pi$-bonds into the resorcinarene macrocycle (highlighted in Scheme 1).

Synthesis conditions, namely the reaction temperature and media, and the influence of the base and the bridging reagent were taken under consideration in order to study the factors affecting the formation of the benzofuran fused macrocyclic structure in more 
A. Formation of a DMF radical in the presence of a base

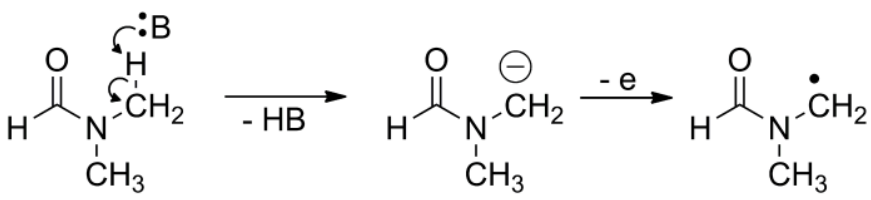

B. Formation of benzofuran ring via radical mechanism

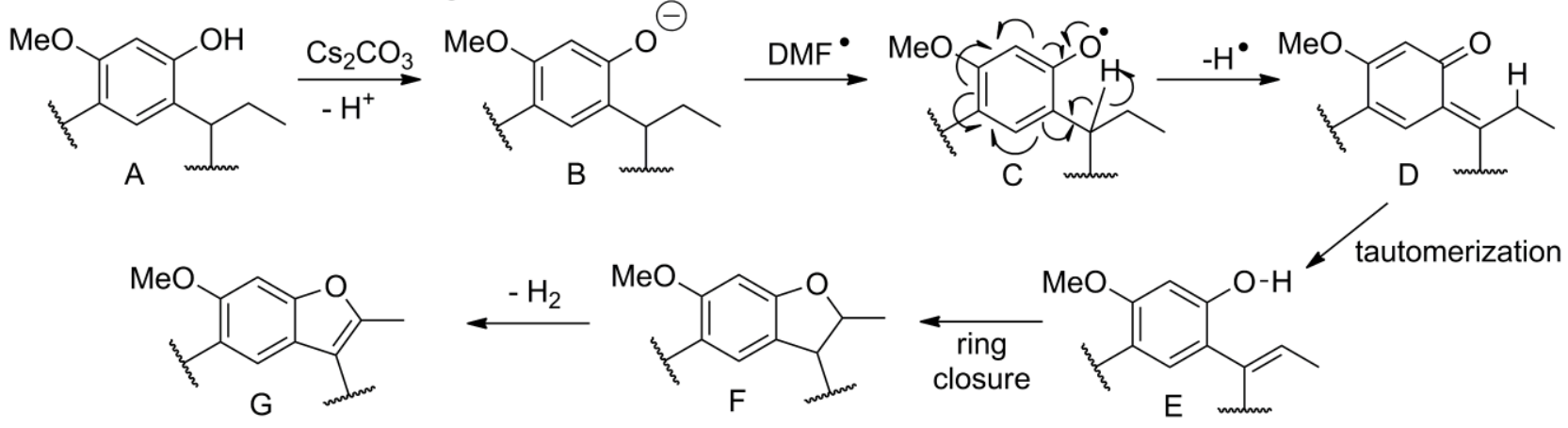

Scheme 2. Proposed reaction mechanism for the benzofuran ring formation via a radical pathway. ${ }^{[19,20]}$

detail (Table 1). Using the aforementioned conditions and allowing tetramethoxy resorcinarene and $\mathrm{Cs}_{2} \mathrm{CO}_{3}$ to react about $60 \mathrm{~min}$ in the specified solvent before the addition of one equivalent (entries 1,2 , 4 and 5) of tetraethylene glycol ditosylate, were set as a standard procedure. The reaction was quenched after one day and the product outcome was analyzed.

When the reaction was performed in DMF at a lower temperature of $60{ }^{\circ} \mathrm{C}$ (entry 2), only the formation of bis-crown derivative 3 was observed. The same result was also obtained in acetonitrile at refluxing temperature. Excluding the bridging unit from the reaction resulted in deprotonation of the resorcinarene hydroxyl groups, and only a mixture of unreacted tetramethoxy resorcinarene and its deprotonated form was obtained. When the reaction was performed with two equivalents of tetraethylene glycol ditosylate (entry 3), the bis-crown derivative 3 was clearly the major product and only a very small amount of the mono-crown derivative 2 formed as a minor product. These observations indicate that solvent (DMF) and a higher reaction temperature together with the $1: 1$ ratio of the starting compounds are the enabling factors on the formation of the benzofuran derivative $\mathbf{1}$.

The exceptional benzofuran ring formation within the resorcinarene skeleton led us to speculate the possible reaction mechanism in more detail. Recent literature presents numerous methods for the synthesis of benzofurans by the formation of the furan ring via intramolecular cyclization of various benzene derivatives. ${ }^{[15]}$ These include the formation of the furan ring from ortho-substituted phenol derivatives e.g. by $\mathrm{Pd}(\mathrm{II})$-catalyzed cyclization of $o$-alkenyl or $o$-alkynyl phenols ${ }^{[16]}$, acid catalyzed dehydration of $o$-hydroxybenzyl ketones ${ }^{[17]}$ or via $\mathrm{Pd}(\mathrm{II})$-mediated Sonogashira cross-coupling of $o$-halophenols with alkynes. ${ }^{[18}$ ] However, while considering the possible reaction pathways for the benzofuran ring formation within the resorcinarene skeleton that lacks an electron deficient $\beta$-carbon atom at the ortho substituent (Scheme 1), the only conceivable alternative seems to be a radical reaction mechanism initiated by DMF radicals. Although DMF is generally considered to be an inert solvent it was recently shown that DMF radicals readily form in the presence of a base,

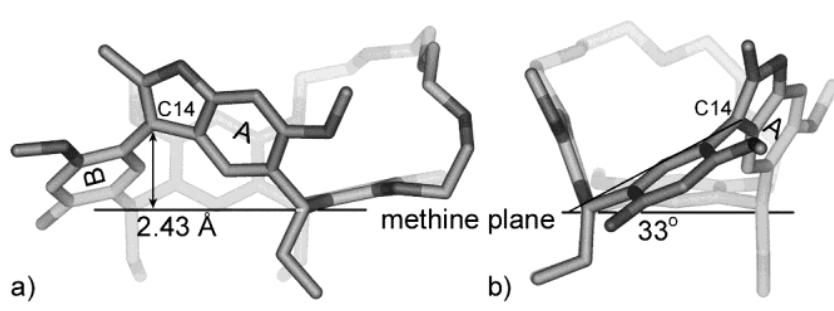

Figure 1. Representative structure (I) of the highly distorted boat conformation of the resorcinarene macrocycle 1: (a) front and (b) side views highlighting the up-shift of the benzofuran unit $\mathrm{A}(\mathrm{C} 14)$ and the inclination of the aromatic unit $\mathrm{B}$ with respect to the methine plane. Hydrogen atoms have been removed for clarity.

(Scheme 2). ${ }^{[19]}$ Therefore, we anticipated that under the applied basic reaction conditions some DMF radicals form and a radical reaction mechanism based on an earlier proposition by Katrizky et $a l .{ }^{[20]}$ takes place (Scheme 2). As such, it is proposed that upon deprotonation by $\mathrm{Cs}_{2} \mathrm{CO}_{3}$ base, the resorcinarene phenoxide $\mathrm{B}$ forms a radical $\mathrm{C}$ in the presence of a DMF radical. The radical $\mathrm{C}$ then loses $\mathrm{H}$. to form the ortho-quinonoid derivative $\mathrm{D}$, which upon tautomerization gives the vinylphenol E. Although the exact reaction mechanism of the ring closure is not yet known, it has been suggested that the intramolecular dehydrocyclization occurs via the addition of the hydroxyl group across the alkenyl side chain to give the intermediate $\mathrm{F}$, which finally upon loss of $\mathrm{H}_{2}$ leads to the formation of the benzofuran derivative $\mathrm{G}^{[20,21]}$

To further verify the proposed mechanism for the formation of a benzofuran ring, the standard synthesis procedure was repeated at $60{ }^{\circ} \mathrm{C}$ and at $90{ }^{\circ} \mathrm{C}$ in the presence of potassium ferricyanide $(0.9$ eq;entries 4 and 5 in Table 1), which is known to act as "oneelectron abstracter" that transforms the deprotonated hydroxyl groups into radicals. ${ }^{[2]}$ The reaction with the radical initiator produced only a small amount (yield $<2 \%$ ) of benzofuran monocrown 1 at $60{ }^{\circ} \mathrm{C}$, but at $90{ }^{\circ} \mathrm{C}$ a slight increase in the yield $(6.1 \%)$ was observed supporting the idea of a possible radical mechanism. 
a) crown outward (top)

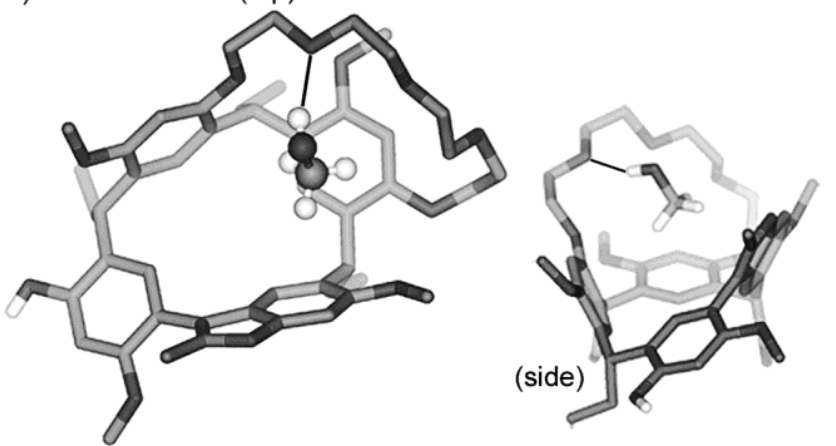

b) crown inward (top)

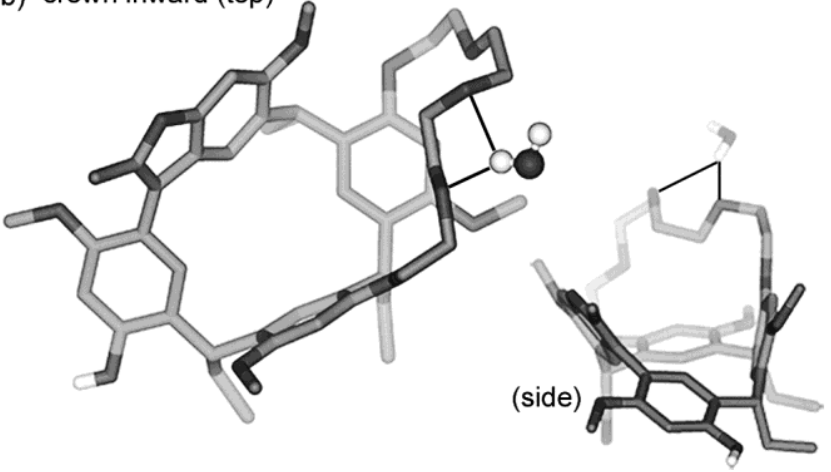

Figure 2. Top and side views of the (a) outward and b) inward conformations of the crown bridge due to endo- and exo-cavity binding of benzofuran derivative 1 with methanol (III) and water molecules (IV), respectively. Non-coordinating hydrogen atoms have been removed for clarity and hydrogen bonds are indicated by black lines.

\section{Structural properties}

Single crystal X-ray diffraction studies revealed the structural and conformational properties of the benzofuran fused resorcinarene $\mathbf{1}$ in solid state. Single crystals were grown by slow evaporation at $8{ }^{\circ} \mathrm{C}$ from acetonitrile (I), chloroform-ethanol (II), chloroform-methanol (III), and ethanol (IV) solutions of $\mathbf{1}$. The resorcinarene benzofuran mono-crown 1 has no symmetry in the resorcinarene cavity, which is composed of three structurally different units (Scheme 1, A-D). In all four structures the resorcinarene skeleton is in a highly twisted boat conformation with a twist angle of $29-31^{\circ}$ (Table S2, Figure S1).

Similarly to the resorcinarene mono-crown derivative $\mathbf{2}$, one end of the cavity is enclosed by a crown ether bridge connecting two adjacent aromatic rings (C-D), while the other end is defined by a horizontal aromatic ring having a free hydroxyl group (B) available for intermolecular hydrogen bonding. The center of the cavity is outlined by two upright aromatic rings (A and C), the other being the benzofuran ring (A) fused into the resorcinarene framework (Figure 1). In comparison to the boat conformations of the biscrown $^{[12]} \mathbf{3}$ and mono-crown ${ }^{[13]} \mathbf{2}$ derivatives, the resorcinarene skeleton of $\mathbf{1}$ is severely distorted due to the $180^{\circ}$ rotation of the lower rim ethyl groups about the methine bridge $(\mathrm{C} 14)$ as it takes part in forming the benzofuran ring. This causes the methine bridge (C14) to shift 2.40-2.79 $\AA$ up from the methine plane (C21-C28-C7, Figure 1a). The distortion of the resorcinarene skeleton is best seen by the inclination of the horizontal aromatic unit B by $30-33^{\circ}$ from the methine plane (Figure 1b), while the conformational parameters of the other three aromatic units (A, C and D) agree well with the typical boat conformation having the dihedral angles of $106-118^{\circ}$

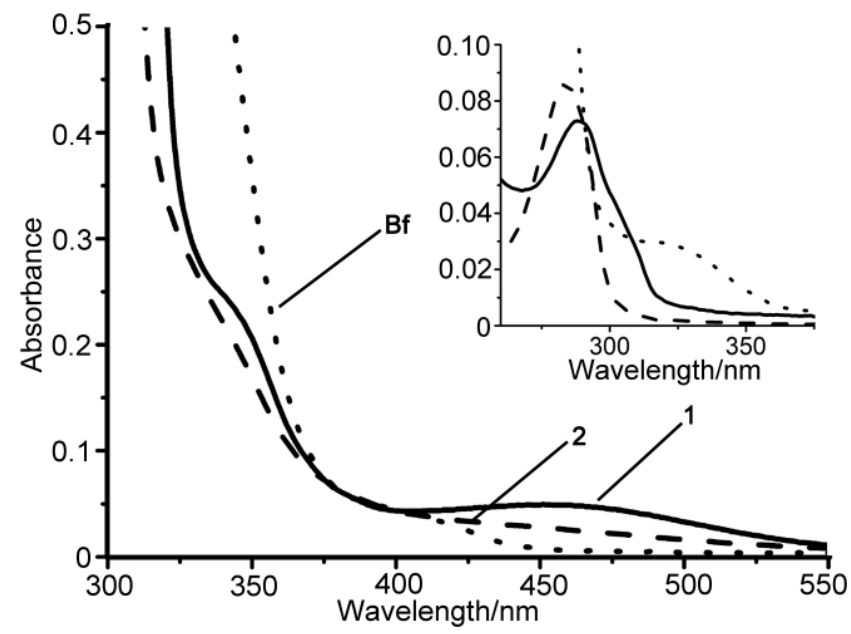

Figure 3. Absorption spectra of compounds 1, 2 and 2,3-benzofuran (Bf) in THF for the emission studies at the excitation wavelengths of 340 and $375 \mathrm{~nm}$. The samples are diluted to $A(375 \mathrm{~nm})=0.07$. The inset shows the absorbance of the compounds for the emission study at the excitation wavelength of $290, \mathrm{~nm}$ in which the concentrations of the sample are scaled to $A(290 \mathrm{~nm})=0.07$.

for the upright aromatic rings (A and C) and $167-177^{\circ}$ for the horizontal aromatic ring (D) (Table S2).

The conformation of the resorcinarene skeleton is very similar in all the four structures (Figure S1), indicating a rigid conformation in which the conjugated system formed by the benzofuran moiety and three aromatic rings is fixed. Notable change is seen in the crown ether bridge as it takes part in solvent binding either in an endo- or exo-cavity mode, which is seen as the outward or inward configuration of the crown ether bridge with respect to the cavity (Figure 2). In the endo-cavity binding a solvent guest is included in the crown pocket by intermolecular hydrogen bonding to the crown ether oxygen (I and III). Similar weak intermolecular interactions prevail in the exo-cavity binding (II and IV), but in this case the solvent molecule is located outside the resorcinarene cavity and the crown ether bridge is bent into the cavity making the average crown pocket diameter of 5.45-5.60 A distinctly smaller than that of $\sim 6.26$ $\AA$ of the outward bent crown ether bridge.

Similar packing motifs to resorcinarene bis- and mono-crown derivatives are observed including self-assembly either to selfinclusion dimer pairs composed of enantiomers of opposite inherent chirality (I, II and IV) or to solvent mediated hydrogen bonded dimer pairs (III). The closest packing into ordered crystal lattices is realized via weak intermolecular hydrogen bonding, $\mathrm{CH}$ - aromatic, aromatic... aromatic and $\mathrm{CH} \cdots \mathrm{O}$ interactions (Figure S2).

\section{Spectroscopic properties}

The effects of the rigid and puckered boat conformation, as well as the effect of the extended conjugated system to the photophysical properties of the benzofuran mono-crown 1 were further investigated in solution by fluorescence spectroscopy. THF was selected as the solvent due to its aprotic nature.

\section{Absorption spectra}

The UV-Vis absorption spectra of the benzofuran mono-crown $\mathbf{1}$, as well as the mono-crown derivative 2 , and 2,3-benzofuran ${ }^{[23]}$ (Bf) selected as reference samples, were measured (Figure 3 ). The 
Table 2 Photophysical characteristics of resorcinarene derivatives $\mathbf{1}, \mathbf{2}$ and 2,3benzofuran $\mathbf{B f}$.

\begin{tabular}{|c|c|c|c|c|c|}
\hline$\lambda_{\mathrm{ex}}$ & Sample & $\varepsilon\left(\mathrm{M}^{-1} \mathrm{~cm}^{-1}\right)$ & $\lambda_{\mathrm{em}}^{\max }(\mathrm{nm})$ & $\Phi_{\mathrm{fl}}$ & Brightness \\
\hline \multirow{3}{*}{$\begin{array}{l}\text { 目 } \\
\text { ○े }\end{array}$} & 1 & 4300.02 & 332 & 0.087 & $375.5(100 \%)$ \\
\hline & 2 & 4412.88 & 319 & 0.065 & $287.7(77 \%)$ \\
\hline & $\mathrm{Bf}$ & 92.37 & - & - & - \\
\hline \multirow{3}{*}{ 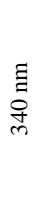 } & 1 & 307.40 & 448 & 0.020 & $6.150(100 \%)$ \\
\hline & 2 & 49.81 & 465 & 0.024 & $1.201(20 \%)$ \\
\hline & $\mathrm{Bf}$ & 18.95 & 360 & - & - \\
\hline \multirow{3}{*}{$\begin{array}{c}\Xi \\
\stackrel{\Xi}{n} \\
\text { n }\end{array}$} & 1 & 86.75 & 452 & 0.0061 & $0.5285(100 \%)$ \\
\hline & 2 & 15.70 & 477 & 0.013 & $0.2053(39 \%)$ \\
\hline & $\mathrm{Bf}$ & 2.29 & 468 & - & - \\
\hline
\end{tabular}

absorption spectrum of 2,3-benzofuran resembles the one presented in the literature. ${ }^{[2]}$ Mono-crown derivatives $\mathbf{1}$ and $\mathbf{2}$ exhibit the same spectral features: two main absorption bands, one at 284 (2) and $290 \mathrm{~nm}(\mathbf{1})$ and a shoulder at 325-350 $\mathrm{nm}$. The slight shift $(6$ $\mathrm{nm}$ ) in the maximum absorption band of $\mathbf{1}$ is due to a bathochromic shift i.e. red shift caused by the longer conjugated system. ${ }^{[25]}$ In addition, unlike 2,3-benzofuran and mono-crown derivative $\mathbf{2}$, benzofuran mono-crown 1 possesses another shoulder around 450 $\mathrm{nm}$. The absorption coefficients $(\varepsilon$, Table 2$)$ of the benzofuran mono-crown derivative $\mathbf{1}$ at wavelengths of 340 and $375 \mathrm{~nm}$ (307.40 and $86.75 \mathrm{M}^{-1} \mathrm{~cm}^{-1}$, respectively) are multiple times higher than the ones obtained for the mono-crown derivative 2 (49.81 and $15.70 \mathrm{M}$ ${ }^{1} \mathrm{~cm}^{-1}$ ) and for 2,3-benzofuran (18.95 and $\left.2.29 \mathrm{M}^{-1} \mathrm{~cm}^{-1}\right)$. However, at the wavelength of $290 \mathrm{~nm}$ the absorption coefficient of $2(4412.88$ $\left.\mathrm{M}^{-1} \mathrm{~cm}^{-1}\right)$ is slightly higher than the absorption coefficient of $\mathbf{1}$ (4300.02 $\mathrm{M}^{-1} \mathrm{~cm}^{-1}$ ). These results indicate that benzofuran ring fused into the macrocycle increases the absorbance at the wavelength range higher than $300 \mathrm{~nm}$ and somewhat reduces it at the wavelength range lower than $300 \mathrm{~nm}$. The increase in the conjugation degree of the macrocycle $\mathbf{1}$ causes the observed spectrum shifts and also explains the growth of absorbance.

\section{Fluorescence spectra}

Steady-state emission spectra of benzofuran mono-crown derivative 1 were measured with three different excitation wavelengths of 290 , 340 and $375 \mathrm{~nm}$ still using mono-crown 2 and 2,3-benzofuran as reference samples (Figure 4, Figure S4). The emission maxima are expressed in Table 2. The multiple emission maxima with various excitation wavelengths indicate that the solution contains various types of emitting components. Potentially these components are in dynamic exchange, for example because of complexation with the solvent molecules. The emission properties of 2,3-benzofuran were not significant and thus it was excluded from further comparison with resorcinarene mono-crowns $\mathbf{1}$ and $\mathbf{2}$.

The quantum yields of mono-crowns $\mathbf{1}$ and $\mathbf{2}$ at the lowest excitation wavelength of $290 \mathrm{~nm}$ are reasonable $\left(\Phi_{1}=0.087\right.$ and
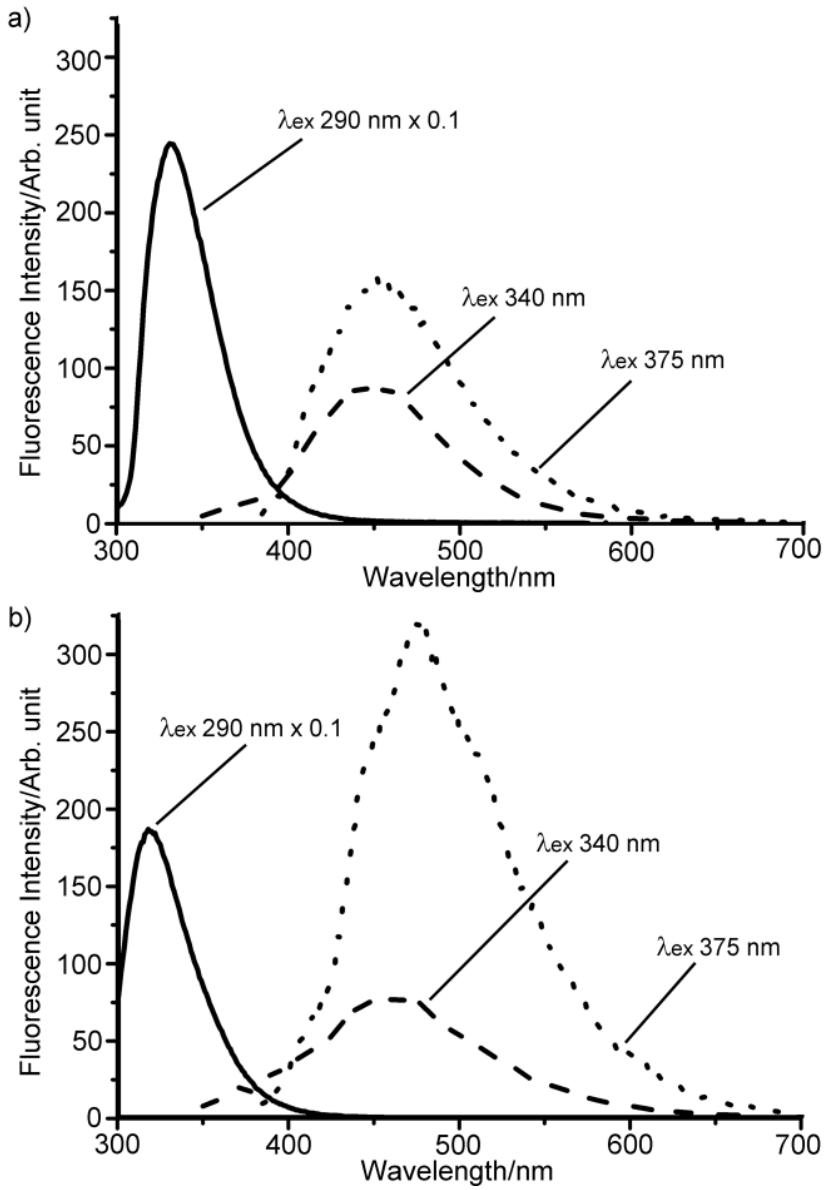

Figure 4. Fluorescence spectra of mono-crown derivatives (a) $\mathbf{1}$ and (b) $\mathbf{2}$ in THF with excitation wavelengths of 290 (solid line), 340 (dashed line) and $375 \mathrm{~nm}$ (dotted line). The intensities of excitation wavelength $290 \mathrm{~nm}$ have been multiplied by 0.1 to fit the scale. Fluorescence intensities are corrected with the number of absorbed photons.

$\left.\Phi_{2}=0.065\right)$, whereas at the excitation wavelengths of $340 \mathrm{~nm}$ $\left(\Phi_{1}=0.020\right.$ and $\left.\Phi_{2}=0.024\right)$ and $375 \mathrm{~nm}\left(\Phi_{1}=0.0061\right.$ and $\left.\Phi_{2}=0.013\right)$ they were almost negligible. At the excitation wavelength of $290 \mathrm{~nm}$ the quantum yield of mono-crown $\mathbf{2}$ is approximately $75 \%$ of the quantum yield of $\mathbf{1}$. A similar trend was also observed with the timeresolved lifetime measurements as the fluorescence lifetime for derivative 2 ( $\tau=1.48 \mathrm{~ns}$ ) was $83 \%$ of the fluorescence lifetime of benzofuran mono-crown derivative $\mathbf{1}$ ( $\tau=1.79 \mathrm{~ns}$, Figure S5a, Table S4). Samples were excited at $290 \mathrm{~nm}$ and decays were monitored at $340 \mathrm{~nm}$. The rigid conjugated structure of mono-crown 1 causes the reduction of the non-radiative pathways which enhances the fluorescence quantum yield compared to mono-crown 2. For the same reason the mono-crown $\mathbf{1}$ shifts the emission maxima toward red compared to mono-crown 2. However, to the contrary of measurement with the excitation wavelength of $290 \mathrm{~nm}$, at excitation wavelengths of 340 and $375 \mathrm{~nm}$ the quantum yields favored the mono-crown derivative 2 over the derivative 1. The quantum yields were $20 \%$ higher at the excitation wavelength of 340 $\mathrm{nm}$, and more than two times higher at $375 \mathrm{~nm}$ for mono-crown 2 . To ensure that such sizeable difference exists, time-resolved fluorescence lifetime measurements were conducted. Samples were excited at $377 \mathrm{~nm}$ and decays were monitored at $440 \mathrm{~nm}$. The averaged fluorescence lifetimes obtained for the derivative $\mathbf{1}\left(\tau_{\text {ave }}=\right.$ $0.91 \mathrm{~ns})$ and derivative $\mathbf{2}\left(\tau_{\mathrm{ave}}=1.93 \mathrm{~ns}\right)$ correlate well with the ratio of the quantum yields at the excitation wavelength of $375 \mathrm{~nm}$ (Figure S5b, Table S4). The reason for the observed phenomena is probably electron or energy transfer between the benzofuran moiety 


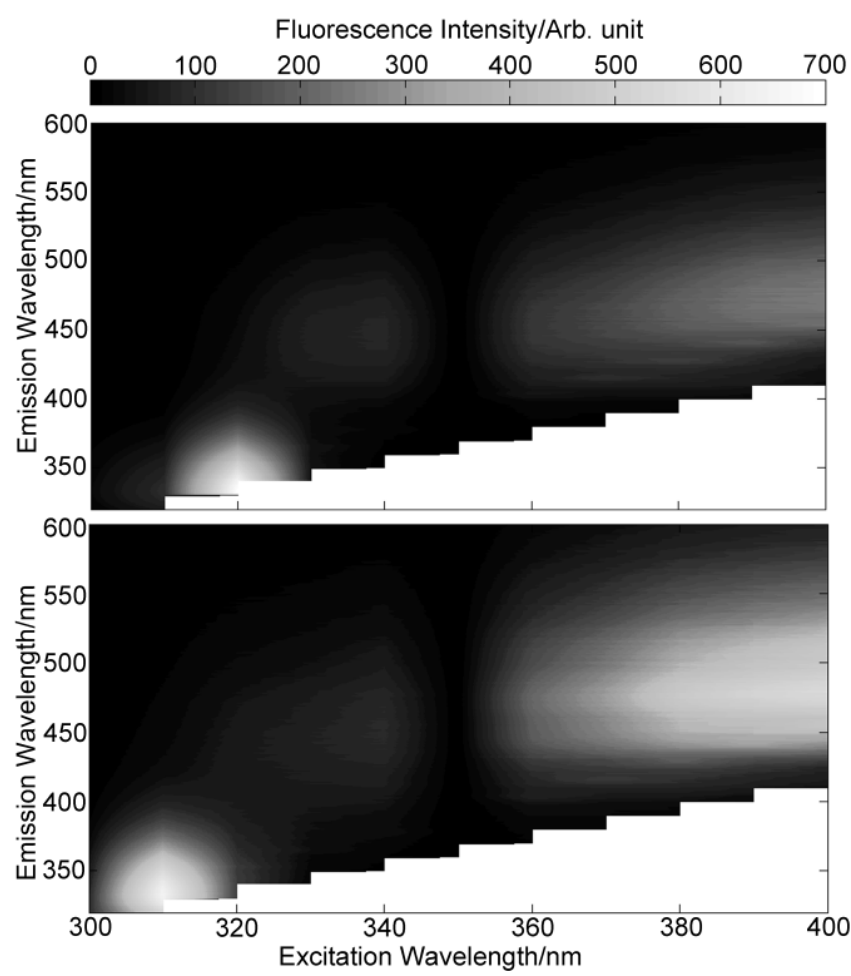

Figure 5. EEM spectrum of benzofuran mono-crown derivative $\mathbf{1}$ (top) and $\mathbf{2}$ (below) in THF. Excitation wavelengths $(\mathrm{nm})$ are on the $\mathrm{x}$-axis, with emission wavelengths $(\mathrm{nm})$ on the y-axis. The colors represent the intensity of the fluorescence, according to the scale. Fluorescence intensities are corrected with the number of absorbed photons.

and the aromatic rings, or an intermolecular proton transfer since in the literature it has been observed that the solvent, $\mathrm{pH}$, and the substitution pattern cause variations to the fluorescence spectra with similar structural features. ${ }^{[25,26]}$ More specific studies of the reasons, however, are out of the scope of this paper.

\section{Brightness}

The quantum yield does not take the concentrations of the samplesinto account whereas brightness values ${ }^{[27]}$ are calculated from quantum yields and absorption coefficients and are thus concentration dependent. In fact, the brightness values confirm the visual observations under UV light $(366 \mathrm{~nm})$ : benzofuran ring clearly increases the fluorescence brightness of $\mathbf{1}$ compared to the mono-crown derivative 2 (Table 2, Figure S3). At the excitation wavelength of $290 \mathrm{~nm}$ the brightness of the benzofuran mono-crown derivative $\mathbf{1}$ is about $20 \%$ higher than that of the mono-crown derivative 2 and at the excitation wavelengths of 340 and $375 \mathrm{~nm}$ the brightness of the derivative $\mathbf{1}$ is significantly higher (80 and $60 \%$, respectively).

\section{EEM spectra}

Emission/excitation matrix (EEM) spectra for the benzofuran monocrown derivative $\mathbf{1}$ and $\mathbf{2}$ were measured to study in more detail, which structural features affect the fluorescence. As expected based on the basic fluorescence measurements three separate fluorescence signals were observed in the EEM spectrum (Figure 5). The shapes of the fluorescence signals at the excitation wavelengths of 300-320 and $330-350 \mathrm{~nm}$ are beautifully round, but the third fluorescence signal (exc. wavelengths 360-400 nm) differs notably from the other two signals as it has a stretched oval shape. The two round fluorescence signals suggest homogeneity and rigidity in certain parts of the structure being most likely caused by the aromatic and the benzofuran rings of the macrocycles.

As observed in the solid state structures, the formation of the benzofuran ring forces the resorcinarene core into a highly distorted and rigid boat conformation. As such, conformational interconversion of the benzofuran mono-crown $\mathbf{1}$ macrocycle is not possible making the structure spectacularly homogenous on that part, and causing the roundness of the two fluorescence signals. Similar phenomenon is also observed with mono-crown 2. Even though it lacks the additional rigidity brought by a benzofuran moiety, the bridging and lack of intramolecular hydrogen bonds favour the boat conformation in the solid state and in solution. ${ }^{[13]}$

A linear relation between the emission and the excitation of the oval shape signal is 0.55 for $\mathbf{1}$ and 0.19 for $2{ }^{[28]}$ This ratio illustrates that the longer wavelength absorbing moieties of compound $\mathbf{1}$ and $\mathbf{2}$ have inhomogeneous broadening. As observed with the basic fluorescence measurement $\left(\lambda_{\mathrm{ex}}=375 \mathrm{~nm}\right)$ the signal is caused by the joint effect of the macrocycle and the crown ether bridge (Figure S6). The broadening together with the fluorescence characteristics of the signals are explained as the crown ether bridge is able to flip between the endo- and exo-positions while providing multiple coordination sites to the crown ether oxygens. The crown bridge flexibility is also seen in the crystal structures (Figure 2) and in the ${ }^{1} \mathrm{H}$ NMR spectrum as the multiplicity of the crown ether proton resonances. ${ }^{[13]}$

\section{Conclusions}

The synthesis of resorcinarene mono- $\mathbf{2}$ and bis-crown $\mathbf{3}$ derivatives in DMF was observed to produce an exceptional benzofuran monocrown by-product $\mathbf{1}$, in which one of the aromatic rings was replaced by a benzofuran moiety. The results of the synthesis studies suggest that the unexpected benzofuran ring formation could happen via a radical pathway as the presence of a radical initiator potassium ferricyanide in the reaction showed a positive effect on the yield of benzofuran resorcinarene mono-crown 1 . The crystal structures revealed that the benzofuran ring forces the resorcinarene skeleton into a highly distorted and rigid boat conformation, which is not observed with the previously studied resorcinarene mono- ${ }^{[13]}$ and bis-crowns $^{[12]}$.

The modified macrocycle structure has a significant effect on the photophysical properties as the brightness of $\mathbf{1}$ was considerably enhanced compared to the structurally simpler mono-crown derivative 2. However, the benzofuran moiety enables more interactions with the surrounding environment causing a decrease in the quantum yields compared to the mono-crown 2 . The fluorescence properties together with the rigid macrocyclic skeleton and the mobile bridge unit enabled the study of the structural characteristics by emission/excitation matrix measurements, which showed that the specific structural characteristics of the benzofuran mono-crown derivative $\mathbf{1}$ can be observed not only in the solid state by the commonly used X-ray crystallography, but also in solution by spectroscopic methods.

\section{Experimental Section}


${ }^{1} \mathrm{H},{ }^{13} \mathrm{C}, \mathrm{HMQC}$ and HMBC NMR spectra were recorded on a Bruker Avance DRX 500 $\mathrm{MHz}$ spectrometer. Accurate ESI mass spectrum was measured with a Micromass LCT ESI-TOF instrument. The calibration was carried out using Leucine enkephalin as an inner standard. Melting point was obtained with a Stuart Scientific SMP3 melting poin apparatus. Tetramethoxy resorcinarene was prepared according to literature procedures. ${ }^{[14]}$ Tetraethylene glycol ditosylate was prepared from tetraethylene glyco by a general tosylation reaction of hydroxyl groups using triethylamine as a base an dichloromethane as a solvent. ${ }^{[29]}$ All other reagents were commercial and used as received. DMF was distilled over Linde type $4 \AA$ molecular sieves and stored ove Linde type $3 \AA$ molecular sieves under $\mathrm{N}_{2}$ atmosphere. $\mathrm{Cs}_{2} \mathrm{CO}_{3}$ was dried in the oven at $120{ }^{\circ} \mathrm{C}$ and stored in a desiccator.

\section{Synthesis of benzofuran mono-crown derivative 1}

A mixture of tetramethoxy resorcinarene ${ }^{[14]}(0.55 \mathrm{~g}, 0.83 \mathrm{mmol}), \mathrm{Cs}_{2} \mathrm{CO}_{3}(1.99 \mathrm{~g}, 6.11$ $\mathrm{mmol})$ and $\mathrm{K}_{3} \mathrm{Fe}(\mathrm{CN})_{6}(0.25 \mathrm{~g}, 0.76 \mathrm{mmol})$ in dry DMF $(40 \mathrm{ml})$ was stirred at $90{ }^{\circ} \mathrm{C}$ (bath temperature) under nitrogen for approximately 60 minutes before the dropwise addition of tetraethylene glycol ditosylate $(0.45 \mathrm{~g}, 0.90 \mathrm{mmol})$ in DMF $(20 \mathrm{ml})$. Brown suspension was stirred at $90{ }^{\circ} \mathrm{C}$ for 24 hours after which it was filtered by suction through a pad of Hyflo Super®. Solvent was carefully removed under reduced pressure. The brown residue was treated once with brine and the separated solid was dissolved in DCM. The organic layer was washed once with brine, treated with decolorizing carbon and dried over $\mathrm{MgSO}_{4}$. Solvent was evaporated under vacuum. Purification was made in two steps by flash chromatography using neutral alumina and chloroform-methano (99.8:0.2) solution as the eluent in the first purification. The second purification was made on silica using chloroform-acetone $(8: 2)$ solution as the eluent affording the product $(0.041 \mathrm{~g}, 6.1 \%)$ as a white solid. The product was recrystallized from methanol for analytical studies. $R_{\mathrm{f}}=0.35\left(\mathrm{CHCl}_{3} /\right.$ Acetone $\left.8: 2\right)$; m.p. $201-203{ }^{\circ} \mathrm{C} ;{ }^{1} \mathrm{H}$ NMR $(500$ $\mathrm{MHz}, \mathrm{CDCl}_{3}, 30{ }^{\circ} \mathrm{C}$ ): $\delta=7.74$ (s, $\left.1 \mathrm{H} ; \mathrm{OH}\right), 7.55$ (s, $\left.1 \mathrm{H} ; \mathrm{ArH}\right), 7.33$ (s, $\left.1 \mathrm{H} ; B f \mathrm{ArH}\right), 7.30$ $(\mathrm{s}, 1 \mathrm{H} ; \operatorname{ArH}), 7.02(\mathrm{~s}, 1 \mathrm{H} ; \operatorname{ArH}), 7.00(\mathrm{~s}, 1 \mathrm{H} ; B f \operatorname{ArH}), 6.73(\mathrm{~s}, 1 \mathrm{H} ; \operatorname{ArH}), 6.68(\mathrm{~s}, 1 \mathrm{H}$ $\mathrm{ArH}), 6.43(\mathrm{~s}, 1 \mathrm{H} ; \mathrm{ArH}), 5.00\left(\mathrm{t},{ }^{3} J_{\mathrm{HH}}=8.1 \mathrm{~Hz}, 1 \mathrm{H} ; \mathrm{CH}\right), 4.64-4.69(\mathrm{~m}, 2 \mathrm{H} ; \mathrm{CH}$ bridge $\left.\mathrm{CH}_{2}\right), 4.45-4.49\left(\mathrm{~m}, 1 \mathrm{H}\right.$; bridge $\left.\mathrm{CH}_{2}\right), 4.22-4.26\left(\mathrm{~m}, 2 \mathrm{H} ; \mathrm{CH}+\right.$ bridge $\left.\mathrm{CH}_{2}\right), 3.96$ $\left(\mathrm{s}, 6 \mathrm{H} ; \mathrm{OCH}_{3}+\mathrm{BfOCH}_{3}\right), 3.91-3.93\left(\mathrm{~m}, 2 \mathrm{H} ;\right.$ bridge $\left.\mathrm{CH}_{2}\right), 3.79\left(\mathrm{~s}, 3 \mathrm{H} ; \mathrm{OCH}_{3}\right), 3.68(\mathrm{~s}$ $\left.3 \mathrm{H} ; \mathrm{OCH}_{3}\right), 3.67\left(\mathrm{~m}, 1 \mathrm{H}\right.$; bridge $\left.\mathrm{CH}_{2}\right), 3.25-3.30\left(\mathrm{~m}, 1 \mathrm{H}\right.$; bridge $\left.\mathrm{CH}_{2}\right), 3.20-3.22(\mathrm{~m}$, $\mathrm{H}$; bridge $\left.\mathrm{CH}_{2}\right), 2.98-3.03\left(\mathrm{~m}, 1 \mathrm{H}\right.$; bridge $\left.\mathrm{CH}_{2}\right), 2.80\left(\mathrm{t},{ }^{3} \mathrm{~J}_{\mathrm{HH}}=8.8 \mathrm{~Hz}, 1 \mathrm{H} ;\right.$ bridge $\left.\mathrm{CH}_{2}\right)$, $2.37-2.42\left(\mathrm{~m}, 1 \mathrm{H} ;\right.$ bridge $\left.\mathrm{CH}_{2}\right), 2.32\left(\mathrm{~s}, 3 \mathrm{H} ; B_{f} \mathrm{CH}_{3}\right), 2.09-2.21\left(\mathrm{~m}, 3 \mathrm{H} ;\right.$ alkyl $\mathrm{CH}_{2}+$ bridge $\left.\mathrm{CH}_{2}\right), 1.92-2.07\left(\mathrm{~m}, 4 \mathrm{H}\right.$; alkyl $\mathrm{CH}_{2}+$ bridge $\left.\mathrm{CH}_{2}\right), 1.81-1.90\left(\mathrm{~m}, 2 \mathrm{H} ;\right.$ alkyl $\mathrm{CH}_{2}+$ bridge $\mathrm{CH}_{2}$ ), 1.56 (overlapping with signal of water, $2 \mathrm{H}$; bridge $\left.\mathrm{CH}_{2}\right), 0.98\left(\mathrm{t},{ }^{3} J_{\mathrm{HH}}=7.2\right.$ $\left.\mathrm{Hz}, 3 \mathrm{H} ; \mathrm{CH}_{3}\right), 0.90\left(\mathrm{t},{ }^{3} J_{\mathrm{HH}}=7.2 \mathrm{~Hz}, 3 \mathrm{H} ; \mathrm{CH}_{3}\right), 0.86 \mathrm{ppm}\left(\mathrm{t},{ }^{3} \mathrm{~J}_{\mathrm{HH}}=7.2 \mathrm{~Hz}, 3 \mathrm{H} ; \mathrm{CH}_{3}\right)$ ${ }^{13} \mathrm{C}$ NMR $\left(126 \mathrm{MHz}, \mathrm{CDCl}_{3}, 30{ }^{\circ} \mathrm{C}\right): \delta=156.2(\mathrm{ArC}), 155.2(\mathrm{ArC}), 155.1(\mathrm{ArC}), 155.0$ $(\mathrm{ArC}), 154.8(\mathrm{ArC}), 153.0(\mathrm{ArC}), 152.9(\mathrm{ArC}), 150.7(\mathrm{ArC}), 132.4(\mathrm{ArC}), 130.2(\mathrm{ArC})$ 127.5 ( $\mathrm{ArC}), 126.0(\mathrm{ArC}), 125.9(\mathrm{ArC}), 124.8(\mathrm{ArC}), 124.4(\mathrm{ArC}), 123.8(\mathrm{ArC}), 122.9$ (ArC), 121.8 (BfArC), 117.0 (ArC), 112.5 (ArC), 111.5 (BfArC), 101.3 (ArC), 100.1 (ArC), 94.1 (ArC), 73.0 (bridge $\mathrm{CH}_{2}$ ), 72.7 (bridge $\mathrm{CH}_{2}$ ), 70.0 (bridge $\mathrm{CH}_{2}$ ), 69.6 (bridge $\mathrm{CH}_{2}$ ), 69.0 (bridge $\mathrm{CH}_{2}$ ), 68.3 (bridge $\mathrm{CH}_{2}$ ), 68.0 (bridge $\left.\mathrm{CH}_{2}\right), 66.9\left(\right.$ bridge $\mathrm{CH}_{2}$ ), $56.5\left(\mathrm{OCH}_{3}\right), 56.4\left(\mathrm{OCH}_{3}\right), 55.8\left(\mathrm{OCH}_{3}\right), 55.1\left(\mathrm{OCH}_{3}\right), 37.8(\mathrm{CH}), 35.6(\mathrm{CH}), 33.7$ (CH), $31.2\left(\right.$ alkyl $\left.\mathrm{CH}_{2}\right), 28.7$ (alkyl $\left.\mathrm{CH}_{2}\right), 26.3\left(\right.$ alkyl $\left.\mathrm{CH}_{2}\right), 14.3\left(\mathrm{BfCH}_{3}\right), 13.1\left(\mathrm{CH}_{3}\right), 12.8$ $\left(\mathrm{CH}_{3}\right), 12.5 \mathrm{ppm}\left(\mathrm{CH}_{3}\right)$; HRMS (ESI-TOF): $\mathrm{m} / z$ calcd for $\mathrm{C}_{48} \mathrm{H}_{58} \mathrm{O}_{11}+\mathrm{Na}^{+}$: 833.3872 $[\mathrm{M}+\mathrm{Na}+]$; found 833.3854 .

Crystal structure determination

The data were recorded on a Nonius Kappa CCD diffractometer equipped with an Apex II detector using graphite monochromatized $\mathrm{CuK} \alpha[\lambda(\mathrm{CuK} \alpha)=1.54178 \AA]$ radiation at a temperature of $173.0 \mathrm{~K}$. The data were processed with Denzo-SMN v0.97.638 $8^{[30]}$ and absoption correction ${ }^{[31]}$ (multi-scan) was applied. The structures were solved by direct methods (SHELXS-97 ${ }^{[32]}$ ), and refinements based on F2 were made by full-matrix least squares techniques (SHELXL-97 $7^{[33]}$ ). Hydrogen atoms were calculated to their idealized positions with isotropic temperature factors ( 1.2 or 1.5 times the $\mathrm{C}$ temperature factor) and refined as riding atoms except for the hydroxyl and water hydrogen atoms, which were located from the difference Fourier map when possible. Crystallographic data have been deposited with the Cambridge Crystallographic Data Center as supplementary publication nos. CCDC 943014-943017. Copies of the data can be obtained free of charge via www.ccdc.cam.ac.uk/data_request/cif.

Spectroscopic measurements

The steady-state absorption, fluorescence and excitation spectra of the samples were diluted in THF so that the absorption was sufficiently low $(A=0.07$ at 290 and $375 \mathrm{~nm})$ to prevent inner filter effect. The spectra were recorded using Perkin-Elmer LAMBDA $850 \mathrm{UV}-\mathrm{Vis}$ spectrophotometer and Varian Cary Eclipse fluorescence spectrophotometer. Excitation-emission matrix (EEM) fluorescence spectrum was obtained by concatenating emission spectra measured every $10 \mathrm{~nm}$ from 310 to $400 \mathrm{~nm}$ using excitation wavelengths $\left(\lambda_{e x}\right)$ from 300 to $400 \mathrm{~nm}$ (10 nm intervals) with $0.5 \mathrm{~s}$ integration time, and a $2.5 \mathrm{~nm}$ slit width. The Raman scattering peaks in the EEM spectrum were corrected with a method described by R. G. Zepp et al.$^{[34]} 1 \mathrm{D}$ emission and excitation spectra were measured using 290,340 and $375 \mathrm{~nm}$ as excitation wavelengths and 340,440 and $480 \mathrm{~nm}$ as emission wavelengths with $0.5 \mathrm{~s}$ integration time and a $2.5 \mathrm{~nm}$ slit width.

Determination of the quantum yields was performed using the same fluorescence spectrophotometer and the excitation wavelengths were 290,340 and $375 \mathrm{~nm}$. The following standards were used: $p$-terphenyl in cyclohexanol $\left(\Phi_{\text {ref }}=0.93\right)$ for the excitation wavelength of $290 \mathrm{~nm},{ }^{[35]} 4$ ',6-diamidino-2-phenylindole (DAPI) in water $\left(\Phi_{\text {ref }}=0.043\right)$ for the excitation wavelength of $340 \mathrm{~nm}{ }^{[36]}$ and coumarin 47 in ethanol $\left(\Phi_{\text {ref }}=0.58\right)$ for the excitation wavelength of $375 \mathrm{~nm} .{ }^{[37]}$ Equation used to determine the quantum yields:

$$
\Phi_{f l}=\Phi_{\text {ref }} \frac{\eta_{\text {solvent }}^{2}}{\eta_{\text {ref.sol. }}^{2}} \frac{F_{\text {sample }}}{A_{\text {sample }}} \frac{A_{\text {ref }}}{F_{\text {ref }}}
$$

where $\Phi_{r e}=$ quantum yield of the reference compound, $\eta=$ refracting index of the solvent, $F=$ Integrated fluorescence intensity and $A=$ absorbance at the excitation wavelength.

Fluorescence decays of the samples in the sub-nanosecond and nanosecond time scales were measured using a time-correlated single photon counting (TCSPC) system consisting of a HydraHarp 400 controller and a PDL 800-D driver (PicoQuant GmBH). The samples were excited at $290 \mathrm{~nm}$ (spectral fwhm $20 \mathrm{~nm}$ ) with the pulsed LED PLS 290-10 at a repetition frequency of $10 \mathrm{MHz}$ and at $377 \mathrm{~nm}$ (spectral fwhm $1.3 \mathrm{~nm}$ ) with the pulsed diode laser LDH-P-C-375 at a repetition frequency of $20 \mathrm{MHz}$ driven by the PDL $800-D$. The output power of the lasers were $5,46 \mathrm{uW} / \mathrm{cm} 2$ and $0.554 \mathrm{~mW} / \mathrm{cm} 2$ for $290 \mathrm{~nm}$ and $377 \mathrm{~nm}$ excitation, respectively. The interference filter was used to detect the emission at $340 \mathrm{~nm}$ and at $440 \mathrm{~nm}$ with a micro channel plate (MCP, R1564-07). The electrical signal obtained from the MCP detector is amplified by a pre-amplifier (PAM 102-M). The time resolutions of the experiments were determined to be approximately $600 \mathrm{ps}$ for $290 \mathrm{~nm}$ and $80 \mathrm{ps}$ for $375 \mathrm{~nm}$ (fwhm of the instrument response function (IRF))

All measurements were carried out at room temperature and at ambient conditions.

\section{Acknowledgements}

We acknowledge Mr. Reijo Kauppinen for his help with the NMR measurements and Dr. Elina Kalenius for her help with the measurement of the accurate mass spectrum. Dr. Kaisa Helttunen is greatly appreciated for fruitful discussions. T.-R.T. acknowledges the financial support from the National Doctoral Programme in Nanoscience (NGSNano). H.L. was supported by the Academy of Finland (SA grant 138063). 
Entry for the Table of Contents

Hey, they fluoresce!

Tiia-Riikka Tero, Kirsi Salorinne, Heli Lehtivuori, Janne A. Ihalainen and Maija Nissinen*... Page - Page

Structural Diversity of

Benzofuran Resorcinarene Leads

to Enhanced Fluorescence

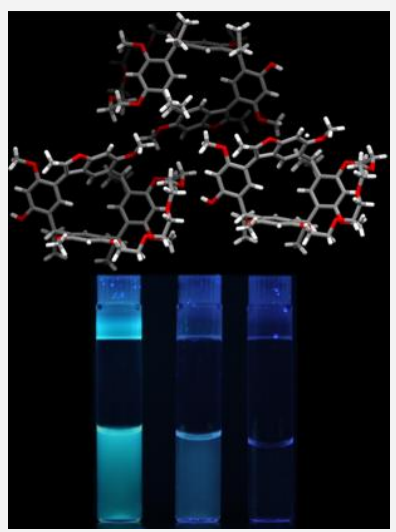

A unique benzofuran ring modified resorcinarene derivative shows enhanced fluorescence properties compared to the conventional resorcinarene macrocycle of the mono-crown derivative. 
[1] For reviews see: a) W. Sliwa, C. Kozlowski, Calixarenes and Resorcinarenes, Wiley-VCH, Weinheim, 2009; b) P. Timmerman, W. Verboom, D. N. Reinhoudt, Tetrahedron 1996, 52, 2663-2704.

[2] See for example: a) D. W. Rudkevich, J. Rebek Jr. Eur. J. Org. Chem. 1999, 1991-2005; b) H. Xi , C. L. D. Gibb, B. C. Gibb, J. Org. Chem. 1999, 64, 9286-9288; c) W. Sliwa, M. Deska, Chem. Heterocylc. Compd. 2002, 38, 646667; d) R. Pinalli, M. Suman, E. Dalcanale, Eur. J. Org. Chem. 2004, 451-462; e) B. W. Purse, J. Rebek Jr. Proc. Natl. Acad. Sci. U. S. A. 2005, 102, 10777 10782; f) M. Nikan, G. A. L. Bare, J. C. Sherman, Tetrahedron Lett. 2011, 52, 1791-1793.

[3] a) A. Shivanyuk, C. Schmidt, V. Böhmer, E. F. Paulus, O. Lukin, W. Vogt, J. Am. Chem. Soc. 1998, 120, 4319-4326; b) C. Schmidt, E. F. Paulus, V. Böhmer, W. Vogta, New. J. Chem 2001, 25, 374-378; c) N. K. Beyeh, D. Fehér, M. Luostarinen, C. A. Schalley, K. Rissanen, J. Inclusion Phenom. Macrocyclic Chem. 2006, 51, 381-394.

[4] E. Kalenius, N. K. Beyeh, J. Jänis, K. Rissanen, Chem. Commun. 2011, 47, 2649-2651.

[5] a) N. K. Beyeh, J. Aumanen, A. Åhman, M. Luostarinen, H. Mansikkamäki, M. Nissinen, J. Korppi-Tommola, K. Rissanen, New J. Chem. 2007, 31, 370-376; b) K. D. Bhatt, H. S. Gupte, B. A. Makwana, D. J. Vyas, D. Maity, V. K. Jain, J. Fluoresc. 2012, 22, 1493-1500.

[6] T. F. Al-Azemi, M. Vinodh, Tetrahedron 2011, 67, 2585-2590.

[7] a) I. Stoll, J. Eberhard, R. Brodbeck, W. Eisfeld, J. Mattay, Chem. Eur. J. 2008, 14, 1155-1163; b) I. Stoll, R. Brodbeck, S. Wiegmann, J. Eberhard, S. Kerruth, B. Neumann, H.-G. Stammler, J. Mattay, Eur. J. Org. Chem. 2008, 5231-5238; c) Y. J. Jang, B.-S. Moon, M. S. Park, B.-G. Kang, J. Y. Kwon., J. S. J. Hong, Y. J. Yoon, K. D. Lee, J. Yoon, Tetrahedron Lett. 2006, 47, 2707-2710.

[8] a) I. Dumazet, P. D. Beer, Tetrahedron Lett. 1999, 40, 785-788; b) S.-T. Yang, D.-J. Liao, S.-J. Chen, C.-H. Hu, A.-T. Wu, Analyst 2012, 137, 1553-1555.

[9] a) Y. Kubo, K. Tsuruzoe, S. Okuyama, R. Nishiyabu, T. Fujihara, Chem. Commun. 2010, 46, 3604-3606; b) O. B. Berryman, A. C. Sather, J. Rebek Jr., Org. Lett. 2011, 13, 5232-5235; c) K. Otsuka, T. Kondo, R. Nishiyabu, Y. Kubo, J. Org. Chem. 2013, 78, 5782-5787.

[10] a) V. A. Azov, A. Schlegel, F. Diederich, Angew. Chem. Int. Ed. 2005, 44 4635-4638; b) I. Pochorovski, B. Breiten, W. B. Schweizer, F. Diederich, Chem. Eur. J. 2010, 16, 12590-12602; c) L. D. Shirtcliff, H. Xu, F. Diederich, Eur. J. Org. Chem. 2010, 846-855.

[11] S. K. Kim, B.-S. Moon, J. H. Park, Y. I. Seo, H. S. Koh, Y. J. Yoon, K. D. Lee, J. Yoon, Tetrahedron Lett. 2005, 46, 6617-6620.

[12] K. Salorinne, M. Nissinen, Org. Lett. 2006, 8, 5473-5476.

[13] K. Salorinne, T.-R. Tero, K. Riikonen, M. Nissinen, Org. Biomol. Chem., 2009, 7, 4211-4217.

[14] M. J. McIldowie, M. Mocerino, B. W. Skelton, A. H. White, Org. Lett. 2000, 2 , 3869-3871.

[15] M. G. Kadieva, E. T. Oganesyan, Chem. Heterocycl. Comp. 1997, 33, 12451258.

[16] K. Rao, R. Tyagi, N. Kaur, D. Kishore, Journal of Chemistry 2013, Article ID 548025, 5 pp., DOI: 10.1155/2013/548025.

[17] A. Lattanzi, A. Senatore, A. Massa, A. Scettri, J. Org. Chem. 2003, 68, 36913694.

[18] a) M. M. Heravi, S. Sadjadi, Tetrahedron 2009, 65, 7761-7775; b) J.-R. Wang, K. Manabe, J. Org. Chem. 2010, 75, 5340-5342.

[19] C. L. Øpstad, T.-B. Melø, H.-R. Sliwka, V. Partali, Tetrahedron 2009, 65, 7616-7619.

[20] A. R. Katritzky, R. Murugan, M. Siskin, Energy \& Fuels 1990, 4, 531-538.

[21] C. Hansch, Chem. Rev. 1953, 53, 353-396.

[22] B. S. Thyagarajan, Chem. Rev. 1958, 58, 439-460.

[23] Commercially available analogue of the benzofuran moiety of mono-crown derivative 1 .

[24] NIST Standard Reference Database 69: NIST Chemistry WebBook, L. Lang (editor) Absorption Spectra in the Ultraviolet and Visible Region, 1961, 2, 357.
[25] L. Cireş, H. Ofenberg, T. Nicolaescu, C. Crăiţă, A. Pollet, J. Lumin. 1998, 79, 91-96.

[26] a) Q. Yang, C. Yan, X. Zhu, Sens.Actuators, B 2014, 191, 53-59; b) M. Gauden, A. Pezzella, L. Panzella, M. T. Neves-Petersen, E. Skovsen, S. B. Petersen, K. M. Mullen, A. Napolitano, M. d'Ischia, V. Sundström, J. Am Chem. Soc. 2008, 130, 17038-17043.

[27] The brightness values were calculated by multiplying quantum yields with absorption coefficients. The brightness of the mono-crown derivative $\mathbf{1}$ was set to $100 \%$ and the brightness of $\mathbf{2}$ is reported relative to that of $\mathbf{1}$.

[28] B. Gobets, H. van Amerongen, R. Monshouwer, J. Kruip, M. Rögner, R. van Grondelle, J. P. Dekker, Biochim. Biophys. Acta Bioenerg. 1994, 1188, 75-85.

[29] See for example: a) D. L. Mohler, G. Shen, Org. Biomol. Chem. 2006, 4, 2082 2087; b) K. Salorinne, M. Nissinen, Tetrahedron 2008, 64, 1798-1807.

[30] Z. Otwinowski, W. Minor in Processing of X-ray Diffraction Data Collected by Oscillation Mode, Methods in Enzymology, Vol. 276: Macromolecular Crystallography, Part A, (Eds. C. W. Carter Jr., R. M. Sweet), Academic Press, New York, 1997, pp. 307-326.

[31] R. H. Blessing, Acta Crystallogr., Sect. A 1995, 51, 33-38.

[32] G. M. Sheldrick, Acta Crystallogr., Sect. A 2008, 64, 112-122.

[33] G. M. Sheldrick, SHELXS97 and SHELXL97, Programs for Crystal Structure Solution and Refinement, University of Göttingen, Germany, 1997.

[34] R.G. Zepp, W. M. Sheldon, M. A. Moran, Mar. Chem. 2004, 89, 15-36.

[35] I. B. Berlman in Handbook of Fluorescence Spectra of Aromatic Molecules, Academic Press, New York, 1971.

[36] T. Härd, P. Fan, D. R. Kearns, Photochem. Photobiol. 1990, 51, 77-86.

[37] G. Jones II, W. R. Jackson, C. Choi, J. Phys. Chem. 1985, 89, 294-300.

Received: ((will be filled in by the editorial staff))

Revised: ((will be filled in by the editorial staff))

Published online: ((will be filled in by the editorial staff) 